\title{
LA DANZA: ALIADA PERFECTA DEL PASADO
}

\author{
Isabel de Naverán Urrutia \\ Universidad del País Vasco / Euskal Herriko Unibertsitatea
}

Resumen

Este ensayo recorre tres aspectos detectados en coreografías reconstruidas en los últimos años: el primero tiene que ver con la controversia de toda reconstrucción, es decir, con la imposibilidad de recuperación de la historia de la danza tal y como fue; el segundo con el archivo en relación al cuerpo, son el estatus del documento en relación a la verdad y por extensión con el papel de lo biográfico en la historia colectiva; y el tercero, suma de los dos anteriores, trata de entender los efectos físicos de una vivencia singular que tiene lugar cuando se habita la técnica creada por un cuerpo distinto al que baila.

Palabras clave: DANZA; RECONSTRUCCIÓN; MEMORIA; ARCHIVO

\section{Abstract}

The present essay shows three aspects of reconstructed choreographies done on the last few years: the first one deals with the controversies of reconstruction itself; that is, with the impossibility to get back the History of dance as it was. The second one tackles archive in relation to body as an entity that saves some kind of corporeal memory; so it has to do as well with the status of the document regarding truth and with the biographic aspects of the collective history. And the third, in addition to the already mentioned, aims at understanding the physical effects of a singular experience that takes place when a dancer practices a body technique of a different time and context from hers.

Key words: DANCE; RECONSTRUCTION; MEMORY; ARCHIVE

De Naverán Urrutia, Isabel. 2015. “La danza: aliada perfecta del pasado”. AusArt 3 (1): 41-53. DOI: 10.1387/ausart.14400

\section{AUSART}


El libro Image(s) mon amour. FABRICATIONS comienza con una declaración de Rabih Mroué que dice "no lo estoy contando para recordarlo. Al contrario, lo estoy haciendo así para estar seguro de que he olvidado. O, por lo menos, para estar seguro de que he olvidado algunas cosas, de que se han borrado de mi mente" $(2013,7)$. Y ese contar para olvidar (en su caso las experiencias vividas durante la guerra y posguerra en Líbano) encierra un deseo mayor: la búsqueda de una fabricación entendida en términos brechtianos que, como nos cuenta Aurora F. Polanco más adelante en el mismo libro, "se aleja de lo orgánico, lo verdadero" $(2013,23)$ y es a su vez un empeño por "deconstruir los mecanismos que rigen las trampas de la representación" (12).

Cuando en 2013 se presentó Performance in resistance ${ }^{1}$ de Isidoro Valcárcel Medina (2011) en la Tate Modern de Londres, el público asistente no entendió que aquello era una obra contemporánea y no una documentación. Irreverente ante los esfuerzos de historización de su obra y de su vida por parte de las instituciones, su gesto consistió en producir las fotografías de acciones realizadas por él mismo en distintas ciudades del mundo entre 1962 y 1993. Acciones que nunca fueron registradas.

Pero ¿es posible documentar hoy algo que sucedió hace treinta o cuarenta años? Su planteamiento parte de esta paradoja. IVM no reconstruye las acciones de entonces, sino que posa ante la cámara el tiempo suficiente para que las fotografías sean tomadas, de manera que la serie de fotografías crea una nueva performance. Un espectador curioso y atento percibirá la contradicción entre la leyenda de la foto (que indica el momento y lugar original de la acción) y su imagen. Vemos, efectivamente, al artista en la fotografía en lo que parece ser el instante de una acción. Sin embargo, tanto el aspecto (su barba blanca o su edad), como los detalles del espacio urbano en que se encuentra (las vestimentas de la gente que pasa por la calle o la arquitectura) delatan la desubicación de la acción en tiempo y en espacio. La resistencia a aceptar la historización como proceso de verificación sume al lector atento en una cápsula del tiempo en la que pasado y presente se vuelven indiscernibles.

Se puede decir que en cierto modo IVM, como Rabih Mroué, también lo cuenta para olvidar, o al menos no lo hace para repetir ni recordar, sino para crear una nueva obra en el presente. Esa nueva obra es crítica con la obsesión actual por reconstruir y recuperar lo que fue. $Y$ eso es lo que parece que no entendieron quienes, durante el debate en la Tate Modern, insistían en preguntas acerca del pasado en lugar de reflexionar sobre la obra presente. La aceleración con que algunas instituciones, y en general los museos, asumen la tarea 
de conservar y preservar la historia, ciega la visión de lo que realmente está sucediendo en el presente. Performance in resistance aspira probablemente a levantar ciertas sospechas respecto a lo que fueron realmente los hechos, o al menos a poner en duda la necesidad de comprobarlos.

En su texto Rabih Mroué continúa: "cuando estoy seguro de que he olvidado, intento recordar qué es lo que he olvidado. $\mathrm{Y}$ al intentar recordar, comienzo a adivinar y a decir: quizás, tal vez, es posible, puede ser, probablemente, parece, da la impresión, no estoy seguro pero, etc." $(2013,7)$.

Desde el olvido, y sin fiarse de su memoria, Mroué lee los restos, los documentos archivados, los registros, como si fuera la primera vez. En esa nueva lectura, intencionalmente escenificada, hace cómplice al espectador a quien, como el espectador atento de IVM, no queda más opción que la de tomar parte en el desvelamiento de la fabricación.

Podemos pensar que es esa misma voluntad (el desvelamiento de una fabricación) la que subyace tras algunas recreaciones recientes de la historia de la danza. Propuestas coreográficas que, en los últimos diez años, han asumido la labor de revisar críticamente su propia historia.

Hoy, que el "impulso de archivo" (Foster 2004) parece denotar una subjetividad contemporánea obsesionada con la recuperación de un pasado extraviado, la relevancia de estas recreaciones reside precisamente en que no tratan de reconstruir el pasado "tal y como fue" (esa sería una labor del historiador de arte, pero no del artista), sino que recurren a él para activar su potencial creativo. Los gestos coreográficos más interesantes nos recuerdan entre otras cosas las contradicciones inherentes al paso del tiempo y su irreversibilidad, el engaño de la memoria, la fragilidad del archivo y del documento considerados como restos de una verdad inapelable, y finalmente el modo en que el relato oficial de la historia de la danza ha llegado hasta nosotros.

En este ensayo me gustaría recorrer tres aspectos que detecto en estas recreaciones coreográficas: el primero tiene que ver con la controversia de toda reconstrucción, es decir, con la imposibilidad de recuperación de la historia de la danza tal y como fue; el segundo es una reflexión sobre el archivo en relación al cuerpo, sobre el estatus del documento en relación a la verdad y por extensión sobre el papel de lo biográfico en la historia colectiva; y el tercero, suma de los dos anteriores, trata de entender los efectos físicos de una 
vivencia singular que tiene lugar cuando se habita la técnica creada por un cuerpo distinto al que baila.

\section{RECONSTRUCCIÓN Y REPOSICIÓN}

Janez Janša es uno de los artistas que más ha insistido en la cuestión de la reconstrucción. Y lo ha hecho oponiendo discursivamente dos conceptos: reconstrucción y reposición. Según él, una reposición siempre trata de recuperar fielmente el pasado y presentarlo hoy tal y como fue, pero nunca podrá reponer el público, ni el momento histórico ni la mirada cultural de entonces. Una reposición que trata de presentar un pasado que se considera intacto, admite confiar que existe una única versión válida acerca de lo sucedido, y por lo tanto respeta y defiende la idea de una verdad irrevocable, indiscutible, que hay que preservar y transmitir.

Para Janša la diferencia entre una reposición y una reconstrucción es que, mientras la reposición utiliza las fuentes históricas únicamente como información para aproximarse fielmente al pasado, una reconstrucción siempre cuestiona el estatus del documento y lo incorpora a un nuevo discurso. Porque la reconstrucción, tal y como la entiende Janša, concede el mismo valor al documento y al hecho. Muestra los procedimientos de la revisión histórica, porque la finalidad de la reconstrucción no es experimentar de nuevo el pasado, sino "experimentar la relación misma con la historia" $(2010,85)$. Por tanto una reconstrucción, según Janša, siempre implica un proceso de reflexividad crítica ya que, en cierto modo "tiene que 'traicionar' el original para poder funcionar en el momento de la reconstrucción" (86).

Estas reflexiones acerca de la relación con la historia surgieron principalmente a raíz del proceso de reconstrucción de Pupilija, Papa Pupilo y los Pupilckecs - reconstruction (2006), una performance de 1969 dirigida originalmente por Dušan Jovanović. Para su reconstrucción Janša contó con documentación audiovisual suficiente y con la memoria del director. La performance fue en su momento muy bien documentada y hoy bien conservada, por tanto las razones para su reconstrucción no fueron las de recuperar una performance histórica para que se conociera hoy, sino reflexionar sobre el presente social, político, económico y cultural a partir de un hecho que formó parte de la historia de Eslovenia. Para ello el director articula distintos niveles de discurso 
simultáneamente a la recreación de algunas escenas de la obra. Una de las maniobras a este respecto más brillantes de Pupilija, Papa Pupilo y los Pupilceks es lo que Janez Janša denomina "efecto zoom": un desplazamiento de la mirada que hace que "lo que miramos nos eluda constantemente. Que constantemente haya algo más que quiera mostrarse ante nosotros"2. Esto sucede porque, cuando creemos estar viendo unas escenas de la obra original, algún dato nos indica que lo que tenemos delante es en realidad una reconstrucción. El grado de auto-referencialidad de la reconstrucción es tan alto que está hilvanado y entretejido con la reactivación del original.

Este desplazamiento de la mirada es el efecto zoom: "un procedimiento de observación en el que los espectadores enfocan, amplían o alejan un determinado segmento, una parte determinada de la performance o de lo que sucede ante ellos o bien usan la misma operación para distanciarse de la performance".

Janez Janša Pupilija, Papa Pupilo y los Pupilceks (2006):

https://youtu.be/z6-8-Re6QcQ

Unos años después, Janez Janša inicia una nueva reconstrucción del mismo director, Dušan Jovanović, pero partiendo esta vez de un planteamiento muy diferente al anterior. Se trata de Monument $G$, una suerte de danza experimental realizada por una bailarina y un músico de la que, al contrario que en la anterior obra, solamente existen unos pocos minutos de la grabación de un ensayo y material fotográfico mal conservado. Sin embargo, al igual que en Pupilja, se cuenta con los intérpretes originales que guardan en su memoria el recuerdo de lo que fue.

Janša decide por tanto estructurar su propuesta en base a esa escasez de documentos y poner esa falta en diálogo con la memoria preservada por quienes vivieron en primera persona Monument $G$ en 1972.

En la danza reconstruida, llamada Monument G2 (2009), el escenario se presenta dividido en dos: de un lado vemos a los intérpretes originales (Jozika Avbelj y Matjaz Jarc) y del otro a dos nuevos intérpretes nacidos tras la fecha de realización de la performance original (Teja Reba y Bostjan Narat). La imagen inicial con la que se encuentra el espectador es la de un desdoblamiento espectral: a la izquierda los cuerpos conocedores de quienes estuvieron allí, delatan el paso del tiempo; a la derecha las dos nuevas siluetas, con vestimentas similares, encarnan la juventud de entonces. Durante la performance aten- 
demos constantemente a un duelo entre las dos coreografías, la bailada por Avbelj, ahora convertida en una experimentada actriz, y por Reba, una joven intérprete. Comparando, tratando de cotejar, verificar y distinguir los fallos y aciertos de ambas, sus figuras se entrelazan y confunden. Paradójicamente, la interpretación de Reba, que no vivió en primera persona lo sucedido en 1972, resulta más fiel a lo que fue la danza en su origen. Quizás porque ella misma se encuentra en un estado físico y mental parecido al que estuvo Avbelj entonces, y porque su cuerpo y su mente no cuentan con la experiencia del paso de los años. Pero también puede ser fruto de la metodología propuesta por Janša para la ejecución de cada una de ellas. Mientras que Janša pide a la intérprete original que, prescindiendo de los documentos, reconstruya la coreografía partiendo solamente de su memoria corporal, propone no obstante a la nueva intérprete que cree la coreografía copiando lo más fielmente posible los documentos (cine y fotografía). El enfoque de esta nueva intérprete parte de un análisis técnico y coreográfico del movimiento original, y de esta manera consigue inesperadamente ser más fiel a la coreografía que la memoria misma de la intérprete original.

Así, Janez Janša revela un nuevo aspecto tocante a la reconstrucción: la sospecha de que ni siquiera la confianza en la memoria corporal es motivo de sosiego cuando a la recuperación del pasado se refiere. Parece que Janša estuviera dispuesto a boicotear todo intento nostálgico de reposición siempre que ésta aspire a detentar una verdad definitiva. En esta nueva reconstrucción el fin, una vez más, es experimentar ese conflicto con la historia para señalar que toda reposición es fallida puesto que es imposible volver a vivir las condiciones culturales, sociales, políticas, o económicas que acogieron una obra y sobre todo, no se puede restituir la mirada del público.

Sin embargo, recuperar la mirada del público es la labor que emprende la artista Olga de Soto en su proyecto historia(s) (2004).

Cuando en 2002 De Soto recibió la invitación del Culturgest de Lisboa para producir un espectáculo en homenaje a El joven y la Muerte de Jean Cocteau (1946), algunos de los primeros interrogantes surgieron en relación al modo en que aquella obra habría sido percibida por quienes asistieron a su estreno: "pienso en las personas que estaban en la sala en 1946, en el público, en aquellos a los que este espectáculo impresionó, marcó. Empiezo a especular con relación a los recuerdos que pueden haber guardado" (De Soto 2004, 1267). Inicia así un proceso de investigación que le llevará dos años y durante el 
cual entrevista a varias personas que asistieron al espectáculo el 25 de junio de 1946 en el Teatro Campos Elíseos de París.

La reconstrucción de historia(s) es una escenificación de los distintos relatos aportados por cada uno de los entrevistados. Distribuidas en distintas pantallas, las imágenes se nos presentan coreografiadas, una vez más maniobradas, por dos intérpretes, un hombre y una mujer. Como un eco de la danza que fue, los intérpretes activan complejos niveles de relación entre imagen y texto, creando la coreografía de El Joven y la Muerte contada desde la memoria de las memorias, la memoria que ha sido filtrada por el paso del tiempo, por más de medio siglo de distancia, con el poso de vivencias, olvidos, tergiversaciones, certezas de cada persona. Olga de Soto activa lo sucedido entonces, en aquel París de la posguerra mundial, recogiendo no solo la descripción de la danza de Cocteau sino, sobre todo, el recuerdo de quienes por primera vez acudían al teatro tras la experiencia traumática de la guerra. Así que se puede decir que De Soto coreografía el testimonio del público, reactivando parcialmente aquella mirada cultural y devolviendo al presente sus interrogantes. Despliega una de las características esenciales de la danza: la memoria corporal y abre la noción de coreografía como una disposición del discurso, al que ciertas verdades siempre se le escapan.

Oga de Soto historia(s) (2004):

https://youtu.be/aFUvSjDHslc

\section{EL CUERPO COMO DOCUMENTO}

El cuerpo es un archivo de memorias, de técnicas, de modos de hacer. $Y$ la danza revela esta realidad sin parar, porque su saber se transmite corporalmente, a través de la copia y la repetición, de la memoria y del olvido. El cuerpo siempre, pero en la danza de manera más intensa, es un dispositivo foucaldiano, un archivo de saberes. Pero cómo acceder a ese archivo. Es lo que se pregunta el teórico André Lepecki en su reciente ensayo El cuerpo como archivo: el deseo de recreación y las supervivencias de las danzas. Su respuesta es rotunda: sólo es posible hacerlo coreográficamente, "pues si algo sabe la coreografía, es que un archivo no almacena: actúa” (Lepecki 2010, 71). Por eso es que actuando, algunas de las coreografías que menciono aquí, 
remitiendo al pasado, perforan el presente para crear una nueva perspectiva, sagaz y crítica, sobre el propio reto que se les propone.

Para hablar del cuerpo como archivo Lepecki recurre a la reconstrucción que de los solos de Dore Hoyer realiza el coreógrafo Martin Nachbar. Nachbar habla de poner en marcha una investigación en la que no solo el coreógrafo visite el archivo, sino que permita al archivo entrar en su cuerpo. Hacer visible el archivo a través del cuerpo, "meter el archivo en el cuerpo: una mutua metamorfosis que conjura, crea, segrega, excreta, modulando puntos críticos donde los elementos virtuales y los reales intercambian sus lugares" (Lepecki 2010, 70).

Urheben Aufheben (2008) es una reflexiva coreografía en la que Martin Nachbar reconstruye algunos solos de la serie Afectos humanos de la coreógrafa alemana Dore Hoyer (1962/64).

La obra consiste en varias escenas en las que Nachbar introduce las dificultades con las que se encuentra a la hora de encarnar los solos de Hoyer. Dificultades debidas en parte a la diferencia entre el cuerpo de Hoyer y el suyo y a las distintas técnicas que han formado ambos cuerpos, el de Hoyer en la danza expresionista, tensa y definida, y el de Nachbar en la nueva danza, blanda e intencionadamente imprecisa. Además, el cuerpo de Nachbar es visiblemente masculino, y trata de introducir en él el archivo afectivo de la bailarina dejando que esta penetre y habite en cada músculo. En un mismo cuerpo, el de Nachbar, habitan dos movimientos: el suyo aprendido corporalmente en la danza, y el de ella, estudiado visualmente en el documento. Ambos dialogan en su interior. Según André Lepecki "Martin interpreta un retorno" $(2010,69)$ invocando explícitamente a la teoría de los afectos de Spinoza, que entendió "el cuerpo como un conjunto de velocidades, intensidades y capacidades de afectar y ser afectado; en otras palabras, el cuerpo como un sistema dinámico de excorporaciones e incorporaciones" (ibidem).

Martin Nachbar Urheben Aufheben (2008):

http://www.numeridanse.tv/fr/video/1884_ua

Quizás sea esa dinámica de excorporaciones e incorporaciones la que provoque una unión de "fuerzas polares", como indica Victoria Pérez Royo, cuando dice que en Urheben Aufheben "se dan simultáneamente una mezcla de perfección técnica con una especie de arrebato emocional" (Pérez Royo 2010: 61). Para desarrollar esta idea de efectos simultáneos, Pérez Royo recurre a 
un concepto clave de Fredric Jameson: la envoltura, que le ayuda a plantear la cuestión de la reversibilidad corporal, ya que "la relación jerárquica entre lo envuelto y la envoltura se mantiene, si bien se hace reversible, desde el punto de vista de que los envoltorios también pueden ser envueltos a su vez" (62).

Por tanto, además de un proceso de envoltura, de retorno, de simultaneidad de vivencias entre la encarnación del pasado y la presencia inexorable del presente, asistimos a un proceso constante de reidentificación corporal.

\section{REVERSIBILIDAD Y REIDENTIFICACIÓN}

La coreógrafa Idoia Zabaleta comentaba en una entrevista ${ }^{3}$ que, tras haber estudiado nueva danza en Ámsterdam y haberse especializado en improvisación con técnicas como Contact Improvisación, Release o Body Weather, sufrió un proceso de reidentificación corporal al retornar a su contexto geográfico de origen, el País Vasco, donde desde niña había ejercitado el cuerpo simultáneamente en gimnasia rítmica de competición y en manifestaciones políticas clandestinas durante la transición del franquismo a la democracia. Tanto la gimnasia como las manifestaciones habían formado un cuerpo asertivo, claro, definido y frontal. Sin embargo en su formación en las nuevas técnicas de danza desarrolladas en la $\mathrm{SNDO}^{4} \mathrm{y}$ herederas de la nueva danza americana, a su vez heredera de los experimentos postmodernos desarrollados en la Judson Dance Theatre, su cuerpo había tenido que aprender a moverse de manera fluida, continua, amable y sin conflictos, aunque también desinteresada y desafectada. Pero al volver a su lugar de origen, la geografía física, mental e ideológica, le recuerda que tras las formas suaves y democráticas de la danza aprendida, hay un puño en alto. Con ese puño en alto decide comenzar su serie de solos Fisuras.

Fisura $n^{\circ 1}$ (2006) comienza con los dos brazos en forma de uve, estirados por encima de la cabeza. Las manos golpean el aire produciendo distintas formas: puños cerrados, dedos en $V$ de victoria, palmas de las manos al frente, etc. El gesto de las manos no solo muestra las distintas ideologías sino también distintas historias del cuerpo: la referencia al ballet, a la danza tradicional, a la gimnasia, al conflicto político, al deseo de comunidad, a los momentos de 
lucha, de reclamo o de placer. En el ballet los brazos de la bailarina son las alas del cisne que baila en el lago.

Fisura $n^{\circ} 3$ : Txoriak (2010) retoma esta imagen de los brazos como alas de pájaro. Esta vez un pájaro destinado a morir. Txoriak parte de una imagen fija, una estampa, a la que acompañan varias canciones. La pieza es una sucesión de estampas, imágenes crónicas aplastadas contra un muro blanco, y sobre ellas una luz cegadora, blanca, que enmarca cada nueva escena. A estas estampas, en las que los brazos en alto vuelven una y otra vez, les acompañan canciones pop y populares que alimentan una ideología nacionalista, victimista, en la que siempre hay un pájaro al que no se permite volar en libertad. Un pájaro cuya voluntad de ser libre se ve truncada por fuerzas del poder y del orden que él no ha elegido y que le son impuestas. Canciones épicas escuchadas desde la infancia a la adolescencia por un cuerpo que a la vez que se entrenaba en competición nacional, era testigo y partícipe de las luchas clandestinas de quienes las cantaban frente al mar.

No me parece casual que Idoia Zabaleta recurriera a la estampa, a la imagen grabada en el cuerpo que ahora se graba en la pared produciendo viñetas. Y son viñetas que pasan de una a otra con humor, si bien un humor negro y ácido, absurdo por momentos, que descoloca y que parece irónico. El reto está en habitar el tiempo de estas imágenes lo suficiente como para volverlas patéticas; quedarse mirando estos caprichosos estampados hasta que su significado original se pierda. $Y$ se pierde en parte gracias a la temporalidad que imprime el gesto congelado en contraste con la música de cada nueva estampa. Pero el reto es también transitar entre una estampa y la siguiente, secuenciar la danza en si misma, vivir el fluir imparable del tiempo, la transformación semántica, su resignificación.

Idoia Zabaleta Fisura n³: Txoriak (2010):

https://youtu.be/pMyW23DlipE

Con este mismo problema de la transición de imagen a gesto temporal debió encontrarse Fabian Barba cuando emprendió la tarea de reconstruir las danzas de la coreógrafa expresionista alemana Mary Wigman y crea el solo $A$ Mary Wigman Dance Evening (2009). En algunos casos tuvo que recurrir a fotografías, estampas, de la coreógrafa bailando sus solos. También para él, siendo un estudiante ecuatoriano en la prestigiosa Escuela P.A.R.T.S. en Bruselas ${ }^{5}$, este trabajo supuso una labor de reidentificación con algunas de las formas que había aprendido en danza moderna en Quito, su ciudad de origen. 
En el caso de Barba, esa reidentificación pasa por reconstruir una selección de solos de Wygman: "visitar esa tradición de danza expresionista alemana me permitía, de cierta manera, restablecer una conexión con la danza moderna que había estudiado en Quito, una cosa muy rara de temporalidades y genealogías artísticas distintas que me permitieron empezar a articular el conflicto que había sentido durante los cuatro años"6.

Fabian Barba A Mary Wigman Dance Evening (2009):

https://youtu.be/McpbGgrY3PU

Si lo pensamos bien, la danza de Mary Wygman funciona aquí como el salto de tigre de Walter Benjamin, aquel recuerdo que "se ilumina en un instante de peligro", una reverberación que rompe, al menos momentáneamente, la sensación de continuidad lineal de la historia, para recordar que hay cuestiones que una y otra vez vuelven, sin justificar su presencia por una lógica teleológica de la causa y el efecto. Como dice Fabian Barba "no existe solo una historia de la danza". Y si habitar la danza de Wigman le permitió reconfortarse con las técnicas aprendidas durante su adolescencia, y encontrar así su identificación en un entorno aparentemente hostil, su reconstitución provocó además una llamada de atención hacia las genealogías imperantes y coloniales de la danza.

Sin embargo él no parece buscar una reposición fidedigna de estas danzas, no aspira a bailarlas tal y como fueron, sino hacerlo de forma que él llama "subjuntiva". Esa forma subjuntiva, en la que algo es sin serlo realmente, en la que algo se convoca sin realizarse plenamente, recoge el efecto que se crea viendo bailar las danzas de ayer de Wigman en el cuerpo de Barba hoy. ¿Qué sucede cuando baila, habita, destila físicamente, los movimientos y expresiones de Wigman? El cuerpo de Fabian es, como lo era el de Nachbar, un cuerpo masculino, de rasgos fuertes, de piel y pelo oscuros. Un cuerpo que delata su geografía y convoca la reflexión acerca no sólo de lo que es ser no ya moderno, sino contemporáneo, y además sobre la técnica de transmisión corporal que hace a la danza delatora de los cuerpos que las habitan.

De nuevo surge la cuestión de la envoltura de la que hablaba Victoria Pérez Royo respecto a Nachbar, un proceso de reversibilidad donde lo envuelto se torna envoltorio a su vez. Un recorrido de aprendizajes y desaprendizajes en el que el contar para olvidar de Rabih Mroué, es en este caso bailar, también para olvidar, o para desaprender. Pero recordemos que en cualquier caso no se trata de rechazar el pasado, sino más bien de volver a leerlo con nue- 
vos ojos, sin la mirada viciada y bajo ciertas sospechas. $Y$ en ese proceso de superposición y reversibilidad se desdibuja el presente para dar paso al pasado, que a su vez se presenta con una nueva intensidad, forma que incide en el ahora para transformarlo.

Esos son los caminos controvertidos pero profundos de la reconstrucción crítica, que no da por sentado el pasado hegemónico, sino que hurga en las intensidades afectivas del cuerpo, para desde ahí cuestionarlo todo. La danza acompaña con todos sus despliegues corporales, mentales y afectivos, esta intensidad.

\section{Referencias}

De Soto, Olga. 2010. “Diario de abordo”. Pp. 125-134 en Hacer Historia: reflexiones desde la práctica de la danza, Isabel de Naverán, ed., CdL\#3 Danza y Pensamiento. Barcelona: Mercat de les Flors

Fernández Polanco, Aurora. 2013. "Fabrications: Image(s) Mon amour." Pp. 10-59 en Image(s) mon amour: Fabrications. Madrid: CA2M

Foster, Hal. 2004. “An archival impulse”. October 110(Autumm): 3-22

Jansa, Janez. 2010. "Reconstrucción 2: Sobre las reconstrucciones de Pupilija, papá Pupilo y Pupilcecs y Monument G”. Pp. 85-113 en Hacer Historia. Reflexiones desde la práctica de la danza, Isabel de Naverán ed., CdL\#3 Danza y Pensamiento. Barcelona: Mercat de les Flors

Lepecki, André. 2010. "El cuerpo como archivo: El deseo de recreación y las supervivencias de las danzas”. Pp. 61-82 en Lecturas sobre danza y coreografía. Editado por Isabel de Naverán y Amparo Écija. Madrid: Artea

Mroué, Rabih. 2013. Image(s) mon amour: Fabrications. Madrid: CA2M

Pérez Royo, Victoria. 2010. “Replantear la historia de la danza desde el cuerpo”. Pp. 53-68 en Hacer Historia: Reflexiones desde la práctica de la danza, Isabel de Naverán ed., CdL\#3 Danza y Pensamiento. Barcelona: Mercat de les Flors

Notas

${ }_{1}$ Performance in resistance fue la respuesta que Isidoro Valcárcel Medina dio cuando desde la oficina de arte y conocimiento Bulegoa z/b (Bilbao) se le planteó reflexionar retroactivamente sobre su obra. Bulegoa z/b en colaboración con IVM respondía así a la demanda del colectivo holandés If I Can't Dance I Don't Want To Be Part Of Your Revolution, que había iniciado un proyecto basado en reconstrucciones de performances significativas del pasado. Tras la respuesta de IVM en la que proponía la realización de las fotografías de acciones efímeras que que nunca fueron documentadas, Bulegoa $\mathrm{z} / \mathrm{b}$ inició un nuevo proyecto, llamado 18 fotografías y 18 historias. El proyecto curatorial de Bulegoa z/b en colaboración con IVM y en el marco del proyecto general de IICD consistió en crear un dispositivo itinerante de relatos que pasó por siete ciudades a lo largo de 2012 y que dio 
lugar al libro 18 fotografías y 18 historias. Para más información: http://www.bulegoa.org/ afueras/18-fotografias-y-18-historias

2 Estas reflexiones acerca de lo que Janez Janša llama "efecto zoom" las recojo de una entrevista que realicé al autor durante su estancia en el País Vasco durante los años 2008 y 2009. En el año 2008, Janez Janša fue invitado a organizar un taller durante el curso de verano de la UPV/EHU Ikusmira. Discursos del cuerpo, que co-dirigí con Idoia Zabaleta; en el año 2009 volvimos a invitar a Janez Janša a organizar un laboratorio en torno al concepto de reconstrucción en Azala. Espacio de creación (Álava). La entrevista no ha sido publicada. La traducción es mía.

${ }^{3}$ Durante el año 2010 y tras el estreno de "Fisura n 3: Txoriak" tuve la oportunidad de entrevistar en varias ocasiones a la coreógrafa. En aquellas conversaciones surgió la cuestión de la reidentificación. Las entrevistas nunca han sido publicadas.

${ }^{4}$ SNDO representa las siglas de School voor Nieuwe Dansontwikkeling (Escuela para el desarrollo de la nueva danza) y se encuentra en Amsterdam. Desde su creación, en 1975, ha sido un referente para la formación y el estudio de técnicas derivadas de lo que se llamó la New Dance (nueva danza) en Estados Unidos, principalmente en Nueva York. A finales de los años sesenta y principios de los setenta, tuvieron lugar en Nueva York cruces interesantes entre las artes plásticas, la música experimental, y la danza postmoderna. Entre los años 1962 y 1964 coreógrafos como Deborah Hay, Lucinda Childs, Steve Paxton o Yvonne Rainer se reunieron en una antigua iglesia del Greenwich Village para poner en cuestión sus aprendizajes previos y experimentar con otros artistas. Nociones que habían sustentado la formación en danza y sus creaciones se pusieron en cuestión. El cuerpo comenzó a trabajarse de otra manera, dando lugar a lo que algunos han denominado como un proceso de "democratización" en la danza, rechazando el virtuosismo, y buscando otras formas de contacto y comunicación entre los cuerpos y hacia el público. A este movimiento se le llamó de la nueva danza, no porque rechazara la danza anterior a ellos, sino porque partía de premisas totalmente distintas. Tuvieron mucha influencia las formas de exploración física basadas en artes marciales o en técnicas orientales de concienciación. El cuerpo ya no se trabaja de manera externa sino interna, a veces sin dar importancia a la estructura visual exterior, sino a un proceso de creación interior y personal. La Escuela para el desarrollo de la nueva danza de Amsterdam recogió algunas de aquellas ideas y enseñanzas para desarrollar sus métodos basados en técnicas distintas a las de la danza moderna o postmoderna.

${ }^{5}$ P.A.R.T.S. The Performing Arts Research and Training Studios (estudios para la formación técnica y la investigación en artes escénicas) es una escuela ubicada en Bruselas, creada en 1995 y dirigida por la coreógrafa Anne Teresa De Keersmaeker. La escuela gana prestigio internacional gracias a su rigor en la relación entre entrenamiento físico y discursivo, en la relación entre la práctica intensiva y el aporte teórico que la acompaña.

${ }^{6}$ Esta declaración y las siguientes referencias a Barba son tomadas en parte de la entrevista siguiente: http://www.artes.uchile.cl/noticias/104682/fabian-barba-no-existe-solo-una-historia-de-la-danza [consultado: 20/04/2015]

$$
\text { (Artículo recibido 29-04-15; aceptado 09-06-15) }
$$

